\title{
TOWARD AN INNOVATIVE STRATEGIC APPROACH FOR SUSTAINABLE MANAGEMENT OF NATURAL PROTECTED AREAS IN ITALY
}

\author{
Ahmadreza Shirvani Dastgerdi ${ }^{1}$, Massimo Sargolini ${ }^{1}$, Ilenia Pierantoni ${ }^{1}$ and Flavio Stimilli ${ }^{2}$ \\ 'School of Architecture and Design, University of Camerino, Viale delle Rimembranze, 63100, Ascoli Piceno, Italy. \\ ${ }^{2}$ School of Advanced Studies, University of Camerino, Via Madonna delle Carceri, 62032, Camerino, Italy. \\ *Corresponding author: Ahmadreza.shirvani@unicam.it
}

Received: November 7"th 2019 / Accepted: August 9 ${ }^{\text {th }}, 2020$ / Published: October $1^{\text {st }}, 2020$

https://DOl-10.24057/2071-9388-2019-143

\begin{abstract}
As the world's largest coordinated network of protected areas, the Natura 2000 network (N2k) encompasses the most valuable and threatened species and habitats in Europe. However, N2k sites have been often criticized due to their rigid management system that focuses only on conservation practice without a strategic vision for linking with the regional plans. This study aims to develop a novel approach for sustainable management of N2k sites in Italy by identifying existing gaps and developing conservation policies. For this purpose, a panorama of the current challenges in the European sites was provided at the first step. Then, the management status of the natural protected sites in Italy was studied by selecting the Umbria Region as the case study. Finally, we develop a strategic approach for boosting the conservation policies and sustainable management of the N2k sites in Italy. The findings highlight that the sustainability of N2k sites requires an inclusive effort in the social, economic, and policymaking fields to meet its conservation objectives. Such an effort encompasses a sophisticated management approach that consists of a network of tools for monitoring the state of conservation, land uses, and socio-economic activities at the regional scale. Furthermore, the integration of environmental policies with regional plans is essential for the sustainable management of the N2k sites.
\end{abstract}

KEY WORDS: Natura 2000 sites, regional planning, conservation, sustainable management

CITATION: Ahmadreza Shirvani Dastgerdi, Massimo Sargolini, Ilenia Pierantoni and Flavio Stimilli (2020). Toward An Innovative Strategic Approach For Sustainable Management Of Natural Protected Areas In Italy. Geography, Environment, Sustainability. https://DOI-10.24057/2071-9388-2019-143

Conflict of interests: The authors reported no potential conflict of interest.

\section{INTRODUCTION}

Stretching across all 27 European Union countries and covering $17.9 \%$ of its land area, the Natura 2000 network (N2k) protects over 27.000 natural sites. As the world's largest coordinated network of protected areas, N2k encompasses the most valuable and threatened species and habitats in Europe (European Environment Agency 2019). The N2k is by far the most significant conservation effort being implemented in Europe. The designation of N2k sites was suggested as the principal strategy for stopping - or at least significantly reducing - biodiversity loss in Europe (Balmford et al. 2003). In addition to biological diversity reservoirs, the natural protected areas are nodes of green infrastructure that provide environmental resilience and ecosystem services; so, these areas contribute to human well-being and wealth on local, regional, and national scales (Bastian 2013; Doak et al. 2015). This network is organized based on the 1979 Birds Directive and the 1992 Habitats Directive (European Commission 2019).

Furthermore, the designation of each site is «irrespective of national or political boundaries» and should be decided using EU-level criteria (European Commission 2011). The N2k consists of Special Protection Areas (SPAs) and Sites of Community Importance (SCls) in a coherent ecological network whose objectives are to guarantee the long-term maintenance of European endangered species and habitats at favorable conservation status. When the lists of SCls are adopted, Member States must designate them as Special Areas of Conservation (SACs) (European Commission 2019). While the selection of SCls is a cooperative process between the member states and the Commission (European Commission 2016), SPAs are usually chosen by the member states with no generally agreed EU-wide criteria (Evans 2012). According to the European Environmental Agency (2019), the total number of the 2621 N2k in Italy covers the total area of $69,302 \mathrm{Km}^{2}$, which is equal to $19 \%$ of the national land area (Fig. 1).

The creation of these sites obliges the authorities to apply relevant management plans, as described in Art. 6 of the Habitats Directive, enforced in Italy by Decree no. $357 / 97$ and subsequent modifications by the President of the Republic. Besides, the designation of N2k sites has been usually criticized as lacking site-selection criteria and neglecting a systematic conservation-planning framework (Hochkirch et al. 2013; Kati et al. 2015; Kukkala et al. 2016). In other words, although the development of $\mathrm{N} 2 \mathrm{k}$ is among the most significant conservation efforts implemented in Europe, there has been a lack of comprehensive and systematic studies that evaluate the efficiency of the network at the regional and local scale (Maiorano et al. 2007).

The development of N2k conservation efforts play a 


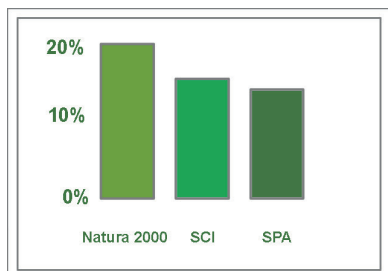

Proportion European land area

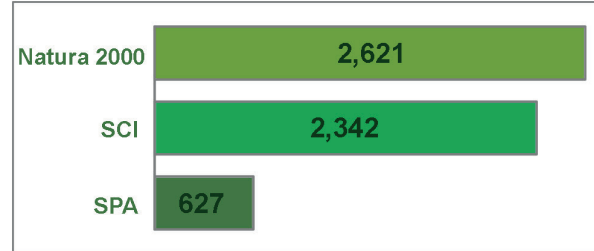

Number of Natura 2000 sites

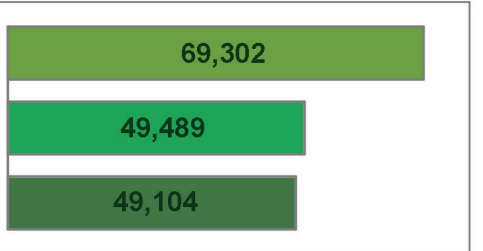

Natura 2000 total areas $\mathrm{Km}^{2}$

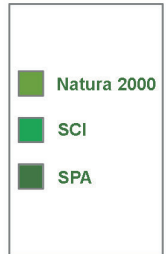

Type

Fig. 1. The N2k Barometer statistics per Italy, retrieved from (European Environmental Agency 2019)

significant role in the protection of biodiversity (Abellán and Sánchez-Fernández 2015), and in this instance, recent findings show that more levels of success could be expected through a coordinated planning system (Kark et al. 2015; Mazor et al. 2013; Pouzols et al. 2014). This study aims to develop a strategic planning approach for sustainable management of N2k sites in Italy through the identification of existing gaps and the improvement of the conservation practice in interaction with regional planning (Sargolini 2013).

\section{MATERIALS AND METHODS}

In this research, we use an interdisciplinary qualitative method to enhance the efficiency of the N2k management framework in Italy. In the first step, we reviewed the recent literature to create a panorama of the current issues and knowledge gaps for the management of N2k in Europe. For this purpose, we collected data from the peer-reviewed sources by searching the keyword 'Natura 2000 site', for the periods from 2009 to 2019. After the selection of the most relevant papers - based on the title and abstract - an open-coding method is applied for the in-depth analysis of the literature.

In the following, we explain how the Umbria Region in Italy has adopted a novel approach for sustainable management of its N2k sites. The Region features 5 SPAs and 97 SACs (Fig. 2). The N2k sites cover about 15\% of the Region and encompass 41 habitats of European interest, of which 11 defined as primary for their particular importance, with 143 animal species (4 are defined as primary), and eight species of plants.

Finally, based on the analysis of the common challenges in the N2k sites and the experiences of the Umbria Region, we develop a strategic approach that facilitates the management of N2k in line with regional plans.

\section{RESULTS}

\section{Common Challenges in N2k Sites}

The analysis of the literature shows some knowledge gaps that should be fulfilled in support of the N2k objectives. Although the «Habitats Directive» represents one of the most potent legal tools in nature conservation, and the importance of N2k sites have been discussed by many scholars (Popescu et al. 2014), still, biodiversity continues to decline in Europe (Hochkirch et al. 2013). In this respect, some researchers have argued if the applied management plan has been well-structured enough to protect the N2k sites in Europe (D'Amen et al. 2013; Gruber et al. 2012; Pullin et al. 2009). A study on N2k sites located in forest areas in six EU member states including Austria, France, Germany, the Netherlands, Spain, and the United Kingdom, revealed that conflicts are related to contradictory stakeholder interests and perceptions, as well as to procedural issues and feelings of exclusion, especially by concerned land user groups (Blondet et al. 2017). A review of $30 \mathrm{~N} 2 \mathrm{k}$ management plans in the Netherlands and France suggests the implementation of conservation measures by a single party, and in particular, the one for which funding from the government is available (Bouwma et al. 2018). In Italy, a study on three bio-geographical regions of Alpine, Continental, and the Mediterranean, reported that the coexistence of many authorities, institutions, and organizations is a common issue for managing N2k sites and implementing conservation activities. Such a problem

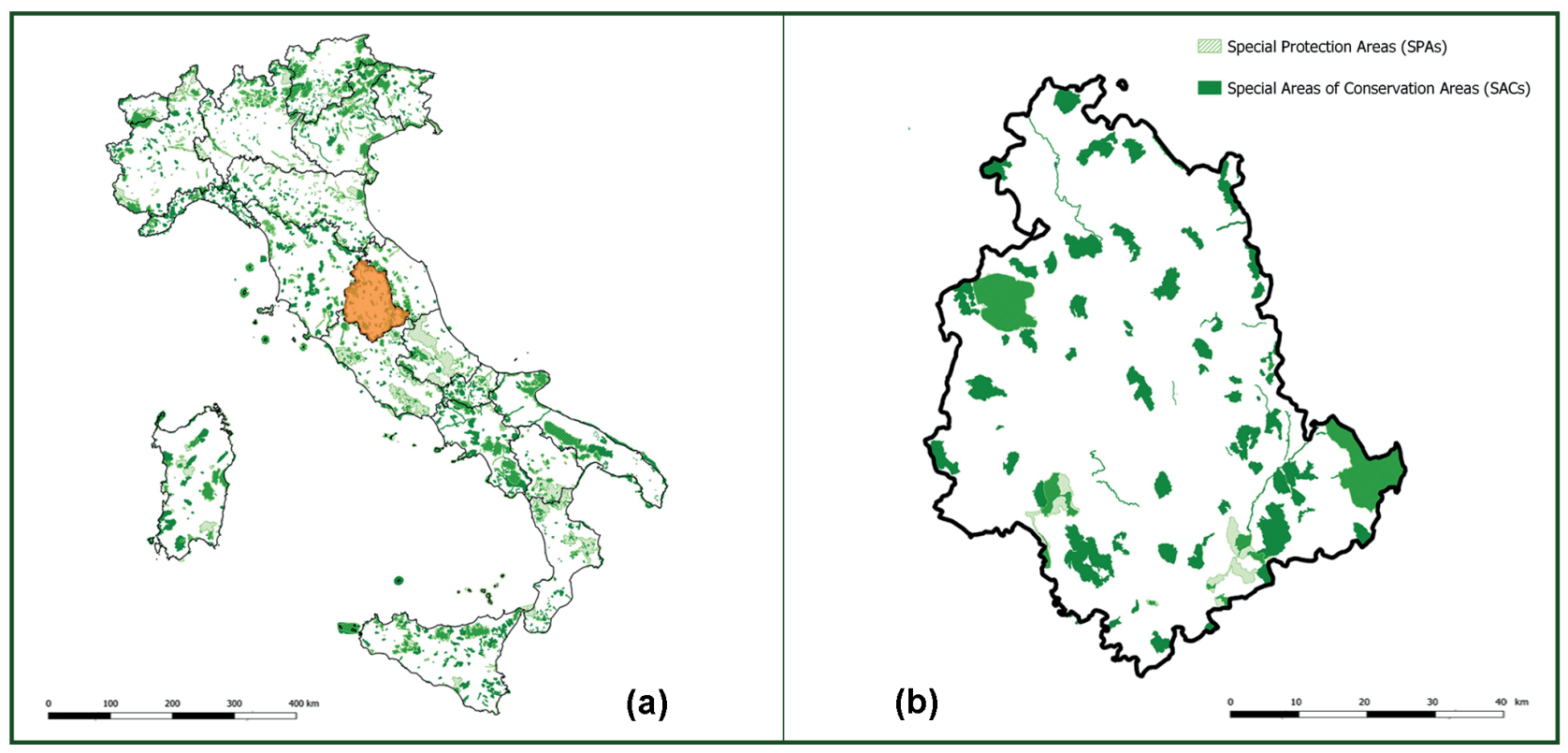

Fig. 2. (a) The Umbria Region in Italy and (b) The distribution of N2k sites 
often represents a bureaucratic burden for stakeholders and results in the fragmentation of government funding and services (Pellegrino, Schirpke, and Marino 2017).

Many studies have developed discussions around the novel conservation approaches (Shirvani Dastgerdi and De Luca 2018; Shirvani Dastgerdi et al. 2019) for sustainable management of cultural heritage sites (De Luca G. and Dastgerdi A.S. 2019a; 2019b; 2019c). Moreover, realizing the inter-relationships between the physical environment, the built environment, and the anthropic environment is emphasized in territorial planning (Battaglia et al. 2019; Magnaghi 2013; Sargolini et al. 2019; Shirvani Dastgerdi et al. 2020). Despite the development of participatory approaches for the management of cultural heritage sites (Dastgerdi and De Luca 2019; Shirvani Dastgerdi and De Luca 2019), there is still an open debate regarding what encompasses a «good» participatory approach in the management of natural resources (Webler and Seth 2006; Wesselink et al. 2011).

According to Blicharska et al. (2016), inadequate engagement of the local community in policymaking and its implementation, negative perception of the network, and lack of flexibility on the part of authorities pose the most significant challenges to the function of the network. It should be noted that insufficient consideration of social aspects risks threatening conservation effectiveness, while integrating local human context in the N2k sites facilitates the biological conservation and promotes socio-economic activities (Oldekop et al. 2016). For instance, the experiences of the Basque country in southern Europe suggests that it is possible to achieve compromise solutions that foster the ecological values of the N2k sites while enhancing other socio-economic aspects, through the integration of different economic and ecological values via a participatory process among diverse social actors (Etxano et al. 2015).

Empirical evidencealso suggests that the sustainability of $\mathrm{N} 2 \mathrm{k}$ sites is subject to various constraints, like the availability of financial resources (Rodela and Udovč 2008), the possible misunderstandings in participatory practices among social actors due to the excess of scientific information (Reed 2008), and the distortion of comprehensive appraisals because of representativeness issues (Kallis et al. 2006). Likewise, distinct narratives between participants (Webler et al. 2004) and emerging tensions between institutional goals and unconstrained deliberation (Kallis et al. 2006) can hinder the sustainability of N2k in the long term.

\section{Management of $2 k$ in Umbria Region}

Umbria Region began initiating environmental policies to ensure long-term protection of N2k sites under the frame of the SUN LIFE project in 2013'. Integrating and coordinating biodiversity conservation in line with the 2020-biodiversity strategy on the one hand, and regional plans $^{2}$ on the other hand, have been among the main objectives of this two-phase project. The first step outlines a cognitive framework through broad and multidisciplinary studies, including the state of biodiversity in the Region, local and supra-local interferences in planning, measures for the management of the N2k sites, and thematic studies on the ecosystem services and green professions. The second phase focuses on the practical management of N2k sites through the available tools provided by the Umbria Region ${ }^{3}$. The framework proposes a novel method to monitor and communicate in N2k sites in the Region (Fig. 3).

Umbria Region has been able to rely on the technical support of a highly qualified partnership with various skills and professions that, capitalized on in the project, allowed reaching all the established objectives. The appropriate State of Conservation has been estimated by dividing the Region into three broad ecosystem categories ${ }^{4}$.

This division allowed considering all the habitats and species present in the Umbria's N2k sites, emphasizing the contexts in which they were most threatened, and providing an assessment that appropriately and consistently relates to conservation.

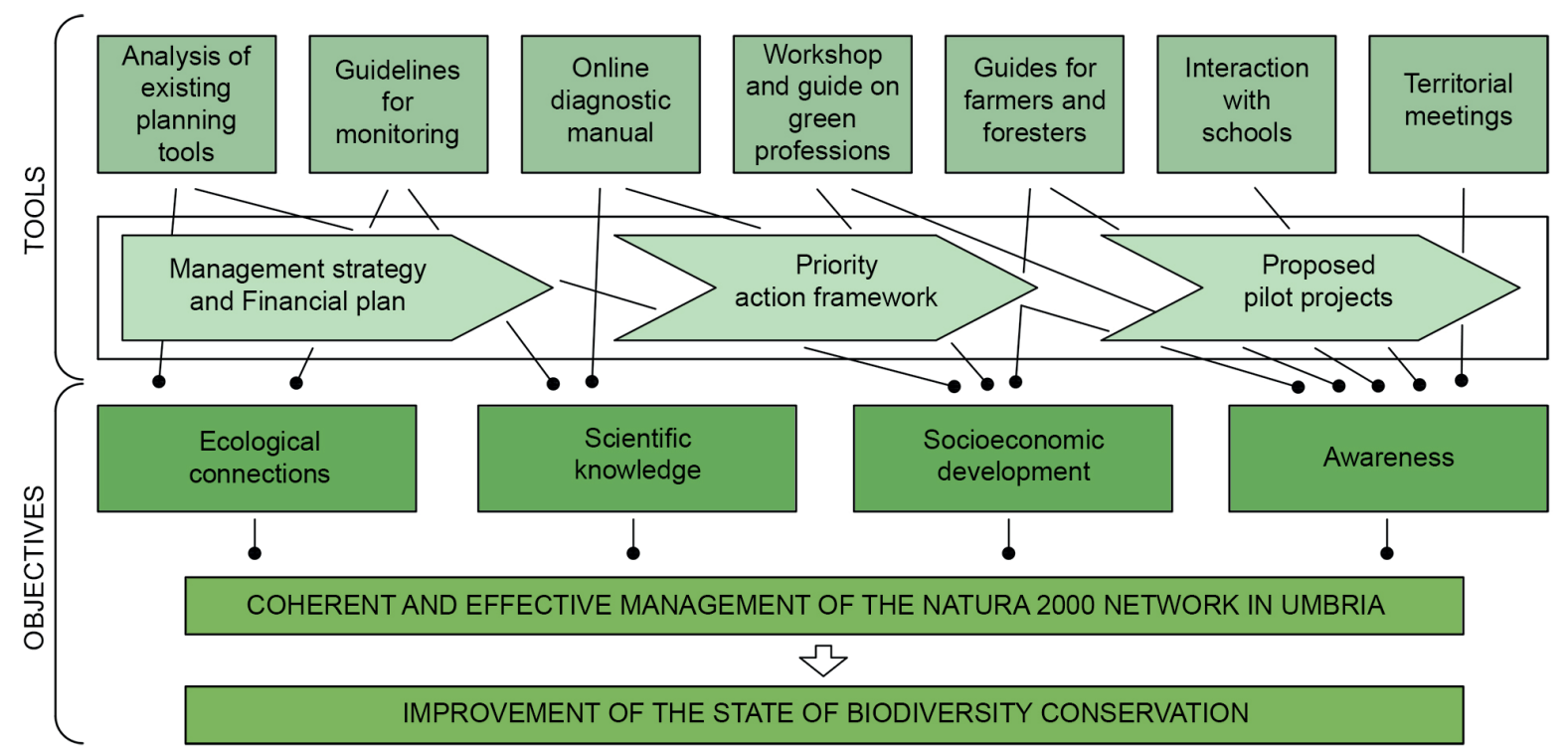

Fig. 3. The used methodology for the management of N2k in the Umbria Region, derived from (Bellisari and Spinelli 2018)

'The title of the project was SUN LIFE - Strategy for managing the Natura 2000 network in Umbria. The work group was composed by: Umbria Region, Comunità Ambiente, University of L'Aquila, University of Camerino, and University of Perugia. You can find a brief description of the project in: Perna P., Pierantoni I., Renzi A., Sargolini M., (eds) (2018), LIST LAB, Milano.

${ }^{2}$ Like land use transformation and associated socio-economic activities.

$3 /$ ncluding management strategy and financial plan, priority action framework, and proposed pilot projects to enhance biodiversity conservation.

${ }^{4}$ The categories are composed of 1) Wet areas, plain and plain-hilly landscapes (up to $600 \mathrm{~m}$ in altitude), 2) Apennine agricultural, forest, and 3) Pasture landscapes (between about 600 and $2450 \mathrm{~m}$ in altitude). 
For synchronizing the dialogue between the planning tools and existing plans, a mosaic of existing plans in the cities was drawn up using data related to the General Regulatory Plans of the 60 municipalities in the Umbria Region. The completion of the mosaic highlighted a rather diversified situation. Although most municipalities have latest-generation plans following LR 11/2005, there is a significant presence of building programs (about $16.5 \%)$, dating back to the 1970s and 1990s, albeit with some updates (Fig. 4). Furthermore, the supra-local plans, including all environmental and development plans at the regional and provincial scale, were also analyzed to understand interferences in planning. The analysis showed that more than 10,000 ha of the Region could still be urbanized within the next 5-10 years. It means that provisions to increase urbanized areas are a more widespread risk, ecologically besieging and suffocating the N2k sites.

Further investigations were carried out into specific plans that provide incentives or strategic indications and norms on circumscribed thematic areas, but which often directly affect N2k sites. Finally, the last phase of the research consisted of comparing the conservation measures and provisions of the plans and programs regarding the same areas of interference. Such an assessment helps to understand whether the plans and programs interfere with the conservation measures. If so, it also highlights whether the interference translates into a criticality, a partial criticality, a lack due to the generic nature of the regulations, or instead if it acts in synergy with the conservation measures.

Based on the assessment method, the methodology brought a formulation of a final comment for each plan that highlights how to implement plans to make them functional in activating the N2k in the forms designated by the Region. In some cases, both at the local and the supra-local level, the study of the various planning tools highlighted problems of «coherence» between the conservation measures established in the management plan and the indications foreseen by ordinary planning. More in general, the fragmentation or even total absence of specific indications seem to emerge regarding N2k sites within the different forms and types of planning. While Umbria Region has an organized, updated regulatory and planning system, the incidence of N2k sites is often relegated to minimal regulatory references, namely, simple references to specific regulations.

Another consideration regards the regional traditionally protected Ecosystem Services (ESs) through administrative tools, with a recent trend and approach that is more aware of the economic tools, including market tools. The assessment of the ESs in Umbria highlights the nature of support services that provide essential goods and regulate ecosystem and cultural processes, supplied by grouping habitats that have ecologically similar characteristics. Beyond supporting the allocation of resources among biodiversity conservation programs and other initiatives of social interest, justifying the budgets destined for biodiversity conservation, and helping define priorities in conservation programs, the economic assessment of the ESs supplied by the N2k in Umbria Region can contribute to establishing the network management strategies that would be best accepted by local populations.

Moreover, according to data from 2012, the N2k businesses in Umbria Region include 1,529 companies with an entrepreneurial density of 12.1 units per 100 residents. Agricultural companies (23.5\%), commerce (20\%), and activities tied to tourism and provision of services (10.0\%)

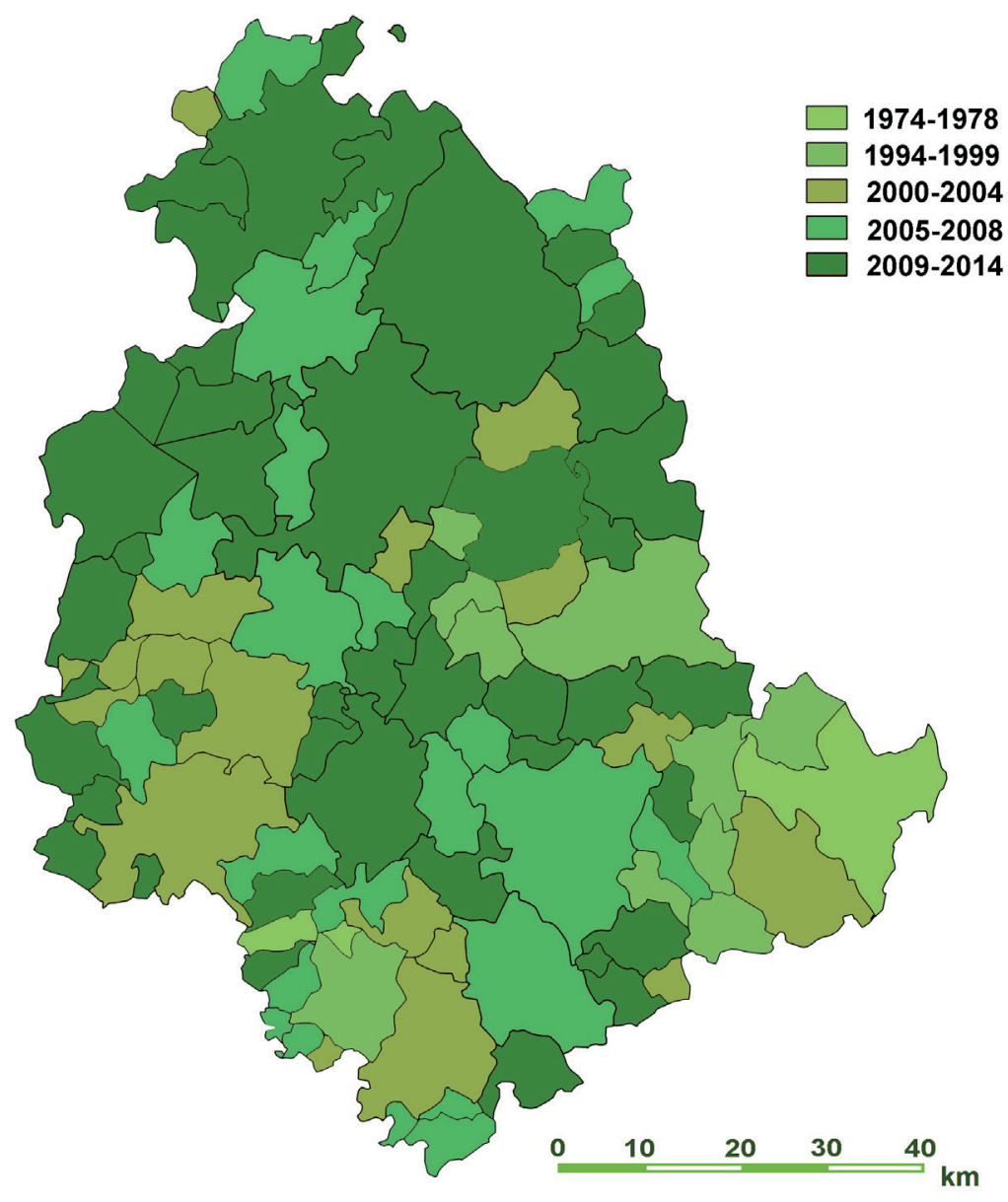

Fig. 4. Geographical distribution of the General Regulatory Plans by the length of time in force, derived from (Marucci, Zullo, Fiorini, and Romano 2018) 
are the most represented activity sectors. Concerning artisan companies and service provision, this stands at $25.6 \%$, higher than the value of N2k areas in central Italy (25\%) by about $0.6 \%$, and by $2.7 \%$ if the equivalent national value of the network is used (22.9\%). These numbers, therefore, represent a particularly active socio-economic fabric, which suggests the opportunity to not only support educational and orientation activities in themselves but also promote a policy that fosters the evolution of a cultural environment favorable to a more effective transition to green professions. The example of the Umbria Region highlights how the N2k sites offer significant possibilities for the near future in some key areas. Ecotourism, or environmental tourism without a shared definition in the literature, is one of these, creating greenways and enhancing the so-called «wildlife economy» (Sargolini and Gambino 2014).

\section{DISCUSSION}

The initial analysis of the Umbria Region has underlined the need to determine a roadmap aimed at overcoming the critical issues regarding the regional regulatory and planning framework and identifying possible solutions. Since the N2k sites in Umbria Region mainly fall within private properties in which productive and economic activities are necessarily included, it is essential to promote forms of management that are coordinated between the public and private realms by providing guidelines and general criteria to specify agreements aimed at managing these areas (Sargolini and Pierantoni 2016). For optimizing the management of the regional network, it is also significant to train personnel from the public institutions and professional associations to expand their competencies regarding the $\mathrm{N} 2 \mathrm{k}$ - management of habitats and species - and also to promote the planning capacity by organizing training courses, seminars, workshops, and conferences.

In the Umbria Region, forestry and farming are significant and widespread activities; therefore, two private guides have been published to develop forestry and farming in the Region. These guides do not aim to be strategic planning documents for forestry and farming activities. They contain no legislative characteristics, but instead offer orientations for good practices to apply the regulations of European Directives to conserve biodiversity: the Habitats Directive (92/43/EEC) and the Birds Directive (2009/147/EEC). In Annex I, some expedients can help improve the state of health of the forests in Umbria, especially those present within N2k sites. The Guide for Foresters aims to illustrate the role of forests and forestry in the N2k in Umbria and to provide the primary users of forest resources with information and advice to best manage forestry activities in a sustainable way. In this guide, 12 good forestry practices are proposed to contribute conserving the forest habitats, such as interventions over small areas, conversions, transformations, maintaining the diversity of tree species, increasing structural diversity, releasing large trees, releasing dead trees and deadwood on the ground, releasing bushes, periods of intervention, methods for concentrating and thinning forests, management of reforestations, and creation of new forests. Moreover, the Guide for Farmers aims to illustrate the role of farming in the N2k sites in Umbria to provide farmers with information and advice to manage agricultural activities in the framework of environmental sustainability. The two guides also provide general information about the N2k in Umbria, accompanied by photographs and maps, including tables of the SACs and SPAs present in the Region.
Under the LIFE+ Programme, Umbria Region has established a Priority Action Framework (PAF) aimed at determining a complete overview of the measures necessary to activate the N2k and the related green infrastructure, specifying the need for financing these measures and tying them to the corresponding financing programs. An integral part of the PAF lies in identifying potential sources of financing, intending to integrate economic resources. For example, the PAF can expect to mobilize direct funds to realize the priority actions, such as European, national, or private funds. Moreover, the financing plan to manage the N2k in Umbria has estimated the active part (resources potentially available to finance the $\mathrm{N} 2 \mathrm{k}$ ) and the passive part (costs to satisfy the need to manage the $\mathrm{N} 2 \mathrm{k}$ ).

To fill the correlation gap between the actors and territorial operators in the Umbria Region, a process to support professions engaged with three distinct but concerted sectors: policy, orientation, and education. The policy defines the support of those institutional and socioeconomic processes among the various actors capable of creating active work policies, orientating professions and skills in the direction of a green economy that includes processes of wildlife economy and circular economy. The orientation implies the cultural interventions necessary to orient both individual behaviors through knowledge and information, and the individual propensity for sustainability in a transverse manner in professional areas. Finally, education means the real, direct, and organizational support for educational activities, at least in the five identified areas, including eco-friendliness, food quality, agricultural systems, cultural activities, and sustainable management of aquatic systems. Furthermore, the direct involvement of the Ministry of Education, universities, and research institutions plays a significant role in the support of technicians, teachers, and business groups that participate in developing schoolwork projects oriented at green jobs.

From the methodological point of view, the guidelines adopted by Umbria Region refer to the most consolidated scientific criteria developed in the sector of monitoring species, populations, and plant communities and habitats with consideration of European guidelines (Evans and Arvela 2011). A hierarchy of species and habitats was developed to identify the real conservation emergencies on the regional scale. It was an indispensable tool for directing and planning monitoring activities appropriately, and for using the resources as well as for managing the interventions. Considerations regarding the ecology and biology of species and habitats were integrated with an analysis of the State of Conservation and anthropic pressures on a regional level, identifying and integrating metrics and indicators in order to provide a classification of conservation priorities. In the realization of an organic monitoring plan, the definition of priorities plays an essential role in evaluating the appropriate methods and times to apply the various protocols. The considerations about priorities were made by dividing the regional territory into three broad and homogeneous areas that allowed for better implementation and quantification of the parameters considered to assess the conditions of species and habitat conservation. These broad areas represent uniform ecological spaces that, considering the division of the territory into bio-geographical regions, allow for an excellent reading of all the parameters considered. Another significant aspect in the Umbria Region was raising awareness in public opinion, which represents a strategic element not only to spread the knowledge about 
the heritage represented by the N2k but also to attribute overall value to its existence. Besides, a path was taken to involve stakeholders in a participatory process that, through territorial interactions, would lead to full sharing both the «Guidelines for farmers and foresters to conserve biodiversity in the N2k» and the "Strategy for managing the N2k in Umbria» (Spilinga et al. 2018). Therefore, each important objective was refined into specific actions that ought to be implemented to reach the effective management of N2k areas in Umbria. For each action, the particular habitats, species and sites were referred to by the action. For each objective, the entities responsible and the primary sources of financing were defined. The strategy was also tested with a specific financial plan that identified and defined the available resources that could be activated.

The current challenges of N2k on the one hand, and the experiences of Umbria on the other, reveals that the N2k sites require knowledge not only on the ecological conservation and management issues (e.g., the status of species and habitats, ways of managing the sites) but also on critical social, economic, political and managerial realities potentially affecting its functionality. To enhance the sustainability of the natural protected areas in Italy, defining the environmental policies at the regional scale is essential, in the sense that they have to address the problems, threats, needs, and expectations behind the development of the regional contexts in which they are situated. At the same time, regional policies are induced or forced to recognize an essential role for environmental policies, in particular, those for protected areas (Sargolini 2006).

Considering the existing conservation challenges at N2k sites in Europe, the implemented strategy in Umbria Region reveals a few essential points for filling the current scientific gaps at the N2k sites. Umbria Region recognizes the social aspects of natural sites through broad and multidisciplinary studies with the participation of highly qualified partnerships with various skills. The Region has created a novel type of communication to raise public awareness about N2k sites through providing guidelines for farmers and foresters, establishing workshops at the school, utilizing the media program, and developing guidelines for visitors. Following the national protocols, the Region integrates the environmental policies with regional plans that have been useful in the monitoring process of natural protected areas. In particular, the experiences of the Umbria Region show a satisfactory interconnection between the financial plan, the Priority Action Framework, and pilot projects, which enhance the management efficiency of the natural protected areas.

\section{CONCLUSIONS}

Although the N2k network is the most significant conservation effort being implemented in Europe, the effectiveness and representativeness of $\mathrm{N} 2 \mathrm{k}$ have the limit to fall often under mere-conservation strategies. The findings of this study reveal that managing the natural protected areas requires dealing with complex socialecological systems, where multiple dimensions such as social, institutional, economic, and ecological ones interact over time and where top-down approaches have been unable to capture this complexity. It means that conservation in Europe should focus more on natural processes, and the N2k system should be integrated into a more comprehensive conservation strategy. The experience of the Umbria Region contributes to developing a multifaceted and strategic management approach for the natural protected areas in Italy, as it consists of a network of tools for monitoring the state of conservation, land uses, and socio-economic activities at the regional scale. For the sustainability of the N2k sites, and in particular, the natural protected areas in Italy, the findings of this study suggest the following remarks and recommendations.

First, initiating the environmental policies in close connection with the urban and regional development promotes the favorable state of biodiversity conservation in the natural areas.

Second, utilizing the current measures at the regional scale may strengthen the N2k management system and improve biodiversity conservation.

Third, the essential factors for developing a medium or long-term conservation strategy are the ability to manage biodiversity in close connection with the various uses and transformations of the land, the maintenance of related socio-economic activities, and the increase of the awareness and knowledge of local communities about the protection of environmental resources.

Fourth, the management approach can include both measures to manage, conserve, and regenerate the landscape in the application of the European Landscape Convention, as well as measures suitable for pursuing balanced development of the green professions and tourism compatible with the conservation of habitats and protected species.

Fifth, the strategy is not a formal planning tool, but does not have limited validity, and will be monitored and possibly updated periodically. The involvement and participation of local communities is an integral part of this strategic conservation approach, as people are informed and educated to implement the best practices for sustainable forestry and farming, with continuous monitoring and the support of technicians and experts.

\section{REFERENCES}

Abellán P. and Sánchez-Fernández D. (2015). A gap analysis comparing the effectiveness of Natura 2000 and national protected area networks in representing European amphibians and reptiles. Biodiversity and Conservation, (24), 1377-1390, DOl: 10.1007/s10531-015-0862-3.

Balmford A., Gaston, K. J., Blyth, S., James A. and Kapos V. (2003). Global variation in terrestrial conservation costs, conservation benefits, and unmet conservation needs. Proceedings of the National Academy of Sciences, DOI: 10.1073/pnas.0236945100.

Bastian O. (2013). The role of biodiversity in supporting ecosystem services in Natura 2000 sites. Ecological Indicators, $24,12-22$.

Battaglia M., Annesi N., Pierantoni I. and Sargolini M. (2019). Future perspectives of sustainable development: An innovative planning approach to inner areas. Experience of an Italian alpine region. Futures, 114, 102468, DOI: 10.1016/j.futures.2019.102468.

Bellisari L. and Spinelli O. (2018). Methodological path to reach the objectives. In P. Perna, I. Pierantoni, A. Renzi, and M. Sargolini (Eds.),

SUN LIFE: strategy for managing the Natura 2000 network in Umbria, 9-11. LISTLAB.

Blicharska M., Orlikowska E. H., Roberge J. M. and Grodzinska-Jurczak M. (2016). Contribution of social science to large scale biodiversity conservation: A review of research about the Natura 2000 network. Biological Conservation, (199), 110-122, DOl: 10.1016/j.biocon.2016.05.007.

Blondet M., de Koning J., Borrass L., Ferranti F., Geitzenauer M., Weiss G., ... Winkel G. (2017). Participation in the implementation of Natura 2000: A comparative study of six EU member states. Land Use Policy, 66, 346-355, DOI: 10.1016/j.landusepol.2017.04.004. 
Bouwma I., Beunen R. and Liefferink D. (2018). Natura 2000 management plans in France and the Netherlands: Carrots, sticks, sermons and different problems. Journal for Nature Conservation, 46, 56-65, DOI: 10.1016/j.jnc.2018.09.001.

D'Amen M., Bombi P., Campanaro A., Zapponi L., Bologna M.A. and Mason F. (2013). Protected areas and insect conservation: Questioning the effectiveness of natura 2000 network for saproxylic beetles in italy. Animal Conservation, (16), 370-378, DOI: 10.1111/acv.12016.

Dastgerdi A.S. and De Luca G. (2019). Improving Cultural Heritage Policy for the Preservation of Historic Minority Quarters. International Journal on Minority and Group Rights, 26, 1-17, DOl: 10.1163/15718115-02704003.

De Luca G. and Dastgerdi A.S. (2019a). Boosting city image for creation of a certain city brand. Geographica Pannonica, 23(1), 23-31, DOI: 10.5937/gp23-20141.

De Luca G. and Dastgerdi A.S. (2019b). Joining Historic Cities to the Global World: Feasibility or Fantasy? Sustainability, 11(9), 1-14, DOl: 10.3390/su11092662.

De Luca G. and Dastgerdi A.S. (2019c). Strengthening the city's reputation in the age of cities: an insight in the city branding theory. City, Territory and Architecture, 6(1), 1-7, DOI: 10.1186/s40410-019-0101-4.

De Luca G., Shirvani Dastgerdi A., Francini C. and Liberatore G. (2020). Sustainable Cultural Heritage Planning and Management of Overtourism in Art Cities: Lessons from Atlas World Heritage. Sustainability, 12(9), 3929, DOI: 10.3390/su12093929.

Doak D.F., Bakker V.J., Goldstein B.E. and Hale B. (2015). What is the future of conservation? In Protecting the wild, Springer, $27-35$.

European Environment Agency. (2019). The Natura 2000 protected areas network. [online] Available at: www.eea.europa.eu/themes/ biodiversity/natura-2000 [Accessed 8 Mar. 2019].

Etxano I., Garmendia E., Pascual U., Hoyos D., Díez M.Á., Cadiñanos J.A. and Lozano P.J. (2015). A participatory integrated assessment approach for Natura 2000 network sites. Environmentand Planning C: Government and Policy,33, 1207-1232, DOI: 10.1177/0263774X15612318.

European Commission. (2011). EC Guidance on undertaking new non-energy extractive activities in accordance with Natura 2000 requirements. Luxembourg: Publications Office of the European Union.

European Commission. (2010). The Birds Directive [online]. Available at: https://eur-lex.europa.eu/legal-content/EN/TXT/HTML/?uri=CE LEX:32009L0147\&from=EN [Accessed 21 May 2020].

European Commission. (2019). Natura 2000 sites designation. [online] Available at:www.ec.europa.eu/environment/nature/natura2000/ sites/index_en.htm [Accessed 8 March 2019].

European Environmental Agency. (2019). Natura 2000 Barometer. [online] Available at:www.eea.europa.eu/data-and-maps/dashboards/ natura-2000-barometer [Accessed 12 May. 2020].

Evans D. (2012). Building the European Union's Natura 2000 network. Nature Conservation, (1)11, DOI: 10.3897/natureconservation.1.1808. Evans D. and Arvela M. (2011). Assessment and reporting under Article 17 of the Habitats Directive. Explanatory Notes \& Guidelines for the period 2007-2012. European Commission, Brussels.

Gruber B., Evans D., Henle K., Bauch B., Schmeller D., Dziock F., .. Dormann C. (2012). «Mind the gap!» - How well does Natura 2000 cover species of European interest? Nature Conservation, (3), 45-62, DOI: 10.3897/natureconservation.3.3732.

Hochkirch A., Schmitt T., Beninde J., Hiery M., Kinitz T., Kirschey J., ... Proelss A. (2013). Europe Needs a New Vision for a Natura 2020 Network. Conservation Letters, 6(6), 462-467, DOI: 10.1111/conl.12006.

Kallis G., Videira N., Antunes P., Pereira Â. G., Spash C. L., Coccossis H., ... Santos R. (2006). Participatory methods for water resources planning. Environment and Planning C: Government and Policy, 24(2), 215-234, DOI: 10.1068/c04102s.

Kark S., Tulloch A., Gordon A., Mazor T., Bunnefeld N. and Levin N. (2015). Cross-boundary collaboration: Key to the conservation puzzle. Current Opinion in Environmental Sustainability, (12), 12-24, DOI: 10.1016/j.cosust.2014.08.005.

Kati V., Hovardas T., Dieterich M., Ibisch P. L., Mihok B. and Selva N. (2015). The challenge of implementing the European network of protected areas Natura 2000. Conservation Biology, 29(1), 260-270, DOI: 10.1111/cobi.12366.

Kukkala A.S., Arponen A., Maiorano L., Moilanen A., Thuiller W., Toivonen T., ... Cabeza M. (2016). Matches and mismatches between national and EU-wide priorities: Examining the Natura 2000 network in vertebrate species conservation. Biological Conservation, (198), 193201, DOI: 10.1016/j.biocon.2016.04.016.

Magnaghi A. (2013). Il progetto locale: verso la coscienza di luogo. Bollati Boringhieri.

Maiorano L., Falcucci A., Garton E. O. and Boitani L. (2007). Contribution of the Natura 2000 network to biodiversity conservation in Italy. In Conservation Biology, DOI: 10.1111/j.1523-1739.2007.00831.x.

Marucci A., Zullo F., Fiorini L. and Romano B. (2018). Analysis and assessment of the means of managing the Natura 2000 Network sites in Umbria. In P. Perna, I. Pierantoni, A. Renzi, and M. Sargolini (Eds.), SUN LIFE: strategy for managing the Natura 2000 network in Umbria, $20-26$. LISTLAB.

Mazor T., Possingham H.P. and Kark S. (2013). Collaboration among countries in marine conservation can achieve substantial efficiencies. Diversity and Distributions, 19(11), 1380-1393, DOl: 10.1111/ddi.12095.

Oldekop J.A., Holmes G., Harris W. E. and Evans, K.L. (2016). A global assessment of the social and conservation outcomes of protected areas. Conservation Biology, 30(1), 133-141, DOl: 10.1111/cobi.12568.

Pellegrino D., Schirpke U. and Marino D. (2017). How to support the effective management of Natura 2000 sites? Journal of Environmental Planning and Management, 60(3), 383-398, DOI: 10.1080/09640568.2016.1159183.

Popescu V.D., Rozylowicz L., Niculae I. M., Cucu A.L. and Hartel T. (2014). Species, habitats, society: An evaluation of research supporting EU's Natura 2000 network. PLoS ONE, 9(11), DOl: 10.1371/journal.pone.0113648.

Pouzols F.M., Toivonen T., Di Minin E., Kukkala A. S., Kullberg P., Kuustera J., ... Moilanen A. (2014). Global protected area expansion is compromised by projected land-use and parochialism. Nature, 516(7531), 383, DOI: 10.1038/nature14032.

Pullin A.S., BÁldi A., Can O. E., Dieterich M., Kati V., Livoreil B., ... Sousa-Pinto I. (2009). Conservation focus on europe: Major conservation policy issues that need to be informed by conservation science. Conservation Biology, (23), 818-824, DOI: 10.1111/j.1523-1739.2009.01283.x.

Reed M.S. (2008). Stakeholder participation for environmental management: a literature review. Biological Conservation, 141(10), 24172431.

Rodela R. and Udovč A. (2008). Participation in nature protection: Does it benefit the local community? A triglav national park case study. International Journal of Biodiversity Science and Management, 4(4), 209-218, DOI: 10.3843/Biodiv.4.4:4.

Sargolini M. and Pierantoni, I. (2016). Neglected landscapes and brownfields: new urban and territorial spaces for new communities. In Un nuovo ciclo della pianificazione urbanistica tra tattica e strategia / a new cycle of urban planning between tactic and strategy. Milan: Planum publisher, 141-150. 
Sargolini M. and Gambino R. (2014). Mountain landscape, vol unico. Actar List Laboratorio Internazionale Editoriale, Trento.

Sargolini M. (2006). Environmental Management for Biodiversity Conservation. In Nature Conservation. Springer, 358-368, DOl: 10.1007/978-3-540-47229-2_35.

Sargolini M. (2013). Urban landscape. Environmental network and quality of life. Milan: Springer, DOI: 10.1007/978-88-470-2880-7.

Sargolini M., Dastgerdi A.S. and Pierantoni I. (2019). Climate Change Challenges to Existing Cultural Heritage Policy. Sustainability, 11 (19), 5227, DOI: 10.3390/su11195227.

Shirvani Dastgerdi A. and De Luca G. (2018). Specifying the Significance of Historic Sites in Heritage Planning. Conservation Science in Cultural Heritage, 18(1), 29-39, DOl: 10.6092/issn.1973-9494/9225.

Shirvani Dastgerdi A. and De Luca G. (2019). Religious differences and radical spatial transformations in historic urban landscapes. Conservation Science in Cultural Heritage, 19(1), 1-13, DOl: 10.6092/issn.1973-9494/10626.

Shirvani Dastgerdi A., Stimilli F., Pisano C., Sargolini M. and De Luca, G. (2019). Heritage waste management. Journal of Cultural Heritage Management and Sustainable Development, 10(1), 76-89, DOI: 10.1108/JCHMSD-07-2019-0087.

Shirvani Dastgerdi A., Sargolini M., Allred S.B., Chatrchyan A. and De Luca G. (2020). Climate Change and Sustaining Heritage Resources: A Framework for Boosting Cultural and Natural Heritage Conservation in Central Italy. Climate, 8(2), 26, DOI: 10.3390/cli8020026.

Spilinga C., Montioni F., Carletti S. and Petruzzi E. (2018). Communication of the SUN LIFE. In P. Perna, I. Pierantoni, A. Renzi, and M. Sargolini (Eds.), SUN LIFE: strategy for managing the Natura 2000 network in Umbria, 79-80. LISTLAB.

Webler T. and Seth T. (2006). Four Perspectives on Public Participation Process in Environmental. The Policy Studies Journal, DOl: 10.1111/j.1541-0072.2006.00198.x.

Webler T., Tuler S. and Tanguay J. (2004). Competing Perspectives on Public Participation in National Park Service Planning: The Boston Harbor Islands National Park Area. Journal of Park \& Recreation Administration, 22(3). [online] Available at: www.js.sagamorepub.com/jpra/ article/view/1466

Wesselink A., Paavola J., Fritsch O. and Renn O. (2011). Rationales for public participation in environmental policy and governance: Practitioners' perspectives. Environment and Planning A., DOI: 10.1068/a44161. 